\title{
REDUÇÃO DO TEOR DE LIMONENO E BERGAPTENO DO ÓLEO ESSENCIAL DE BERGAMOTA ADSORVIDO EM SÍLICA GEL PELO $\mathrm{CO}_{2}$ - SUPERCRÍTICO ${ }^{1}$
}

\author{
Júlio Maria de Andrade ARAÚJO ${ }^{2, *}$, Ana Paula Santa Fé FARIAS ${ }^{3}$
}

\section{RESUMO}

Testou-se a utilização do $\mathrm{CO}_{2}$ supercrítico na extração seletiva de compostos oxigenados (linalol e acetato de linalila) contidos no óleo essencial de bergamota (Citrus bergamia Risso), var. bergamia, adsorvido em sílica gel contendo baixo teor de limoneno e bergapteno. A densidade do dióxido de carbono e a temperatura de extração foram otimizadas, e os extratos obtidos foram analisados por cromatografia. Nas condições estudadas, observou-se uma redução de $72 \%$ no teor de limoneno e $92,5 \%$ para o bergapteno, sendo extraídos $52 \%$ de linalol e 69,4\% de acetato de linalila.

Palavras-chave: extração supercritica; linalol; acetato de linalila.

\section{SUMMARY}

LIMONENE AND BERGAPTEN REDUCTION FROM BERGAMOT ESSENCIAL OIL ADSORBED IN SILICA-GEL BY SUPERCRITICAL CARBON DIOXIDE. The use of supercritical $\mathrm{CO}_{2}$ was tested in the selective extraction of the limonene contained in the bergamot essential oil (Citrus bergamia Risso), var. bergamia, and posterior concentration of the oxygenated fraction (linalool and linalyl acetate) with reduced bergapten. It was used silica gel as adsorbent to improve the fractionation between the components of interest. It was tested, firstly, the extraction temperature and carbon dioxide density ideals for the removal of the limonene. Then, in a second stage was determined the best temperature and density for the linalool and linalyl acetate extraction with reduced bergapten. After extraction, the essential oil extract with $52 \%$ of linalool and $69.4 \%$ linalyl acetate had $72 \%$ less limonene and 92.7 less bergapten.

Keywords: supercritical $\mathrm{CO}_{2}$; linalool; linalyl acetate.

\section{1 - INTRODUÇÃO}

O óleo essencial de bergamota é obtido pelo processo de raspagem da casca (Pellatrice), apresentando em sua composição maior quantidade de compostos oxigenados do que a normalmente encontrada em óleos de outras frutas citricas $[2,5,16]$. Seus principais constituintes oxigenados são o linalol e o acetato de linalila (Figura 1). Ė utilizado na aromatização de balas, chás, sorvetes e tabaco, conferindo a estes produtos um aroma adocicado e refrescante. Na indústria de perfumaria é aplicado em loções, colônias citricas, sabonetes, cremes, maquiagem e loções bronzeadoras dando um aroma delicado e refrescante a estes produtos $[8,9,10$, $12,13]$.

O limoneno, principal componente de outros óleos de citrus, não ultrapassa 55\% no óleo de bergamota e, além de não contribuir para o aroma do óleo, age como carreador para os compostos oxigenados facilitando, assim, a oxidação do óleo quando em contato com o ar. $\mathrm{O}$ acetato de linalila e o linalol estão presentes no óleo em concentrações variáveis entre 15 e $40 \%$ e 1,5 a $20 \%$ respectivamente $[5,12,16]$.

O maior problema para sua aplicação na indústria de perfumaria é a presença de bergapteno na fração nãovolátil do óleo. Esta substância em peles muito sensíveis, tem efeito fototóxico podendo causar dermatites e hiperpigmentação, fazendo com que seu uso em cremes,

Recebido para publicação em 12/09/2000. Aceito para publicação em 09/12/2002 (000519).

2. Departamento de Tecnologia de Alimentos - Universidade Federal de Viçosa, CEP - 36571-000, Viçosa-MG

* A quem a correspondência deve ser enviada. loções e perfumes fique restrito [12, 18]. O bergapteno torna-se biologicamente ativo quando exposto a radiação ultravioleta (320 a 400nm), e alguns de seus efeitos biológicos têm sido atribuídos à habilidade deste composto em se intercalar com o DNA celular, membranas e proteínas [19]. O efeito mutagênico do bergapteno depende de sua concentração no óleo. Quantidades acima de $0,002 \%$ em fragrâncias já causam reações adversas sobre a pele $[11,18]$.

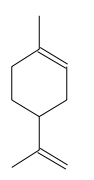

(1)

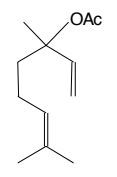

(2)

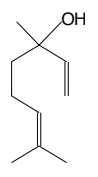

(3)

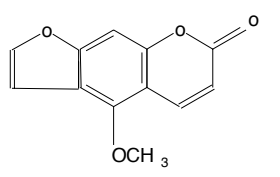

(4)
FIGURA 1. Estruturas químicas de limoneno (1), linalol (2), acetato de linalila (3) e Bergapteno (4).

Com o propósito de eliminar os problemas causados pelo bergapteno, algumas indústrias estão utilizando óleo essencial de bergamota debergaptenizado, e os processos mais utilizados são a destilação a vapor e a cromatografia em coluna [7, 15]. Recentemente, o método de extração pelo $\mathrm{CO}_{2}$-supercrítico vem sendo testado como alternativa em substituição àqueles convencionais atualmente em uso [1, 3, 6, 11, 14].

Este trabalho tem como objetivo examinar a possibilidade do uso do dióxido de carbono supercrítico sob várias condições de extração, na redução do teor de limoneno e bergapteno do óleo essencial de bergamota. 


\section{2 - MATERIAL E MÉTODOS}

\section{1 - Amostra}

O óleo essencial de bergamota foi doado pela empresa IFF-Essências e Fragâncias Ltda e armazenado a $7^{\circ} \mathrm{C}$, ao abrigo da luz.

\section{2 - Reagentes}

O dióxido de carbono foi obtido da White Martins (grau 4.7). Os compostos bergapteno, limoneno, acetato de linalila, linalool, cumarina, tetradecano e sílica gel 70, 300mesh foram obtidos da Sigma. Os solventes hexano, isopropanol e etanol grau cromatográfico foram obtidos da Merck.

Soluções estoque de cumarina (padrão interno): preparou-se uma solução de 50,1 mg em balão volumétrico de $50 \mathrm{~mL}$ completando-se o volume com etanol, o que resultou numa concentração de $0,98 \mathrm{mg} \cdot \mathrm{mL}^{-1}$. Para o bergapteno, utilizou-se 14,6mg em etanol, num balão de $10 \mathrm{~mL}$. Soluções de trabalho foram diluidas em etanol, obtendo-se variação na concentração entre 0,0014 a $0,058 \mathrm{mg} \cdot \mathrm{mL}^{-1}$, as quais foram filtradas em seringas com filtro de nylon $0,45 \mu \mathrm{m}$ para as análises por cromatografia liquida.

Para análises em cromatografia de fase gasosa, prepararou-se as soluções-padrão de limoneno $(96,7 \%)$, linalol $(95,6 \%)$ e acetato de linalila $(96 \%)$ em hexano, variando a concentração de $480 \mu \mathrm{g} \cdot \mathrm{mL}^{-1}$ a $974 \mu \mathrm{g} \cdot \mathrm{mL}^{-1}$, $49 \mu \mathrm{g} \cdot \mathrm{mL}^{-1}$ a $9870 \mu \mathrm{g} \cdot \mathrm{mL}^{-1}$ e $51 \mu \mathrm{g} \cdot \mathrm{mL}^{-1}$ a $1031 \mu \mathrm{g} \cdot \mathrm{mL}^{-1}$, respectivamente. Retirou-se $1,0 \mathrm{~mL}$ das soluções diluídas nas diferentes concentrações, e a cada uma foram adicionadas $20 \mu \mathrm{L}$ da solução de padrão interno (tetradecano, $1,0 \mathrm{~mL} / 10 \mathrm{~mL}$ hexano).

\section{3 - Equipamentos}

Utilizou-se o extrator HP 7680A equipado com restritor variável, permitindo o controle independente de fluxo e pressão, extrator de $7,0 \mathrm{~mL}$ de volume interno reduzido com espaçador cilindrico de vidro maciço de $6,7 \mathrm{~cm}$ de comprimento e $1,0 \mathrm{~cm}$ de diâmetro e coletor de octadecilsilica (ODS).

O cromatógrafo liquido HP 1050 equipado com loop de $20 \mu 1$ e detector de UV-visivel, pré-coluna Hyperasil $(20 \mathrm{~mm} \times 5 \mu \mathrm{m} \times 4 \mathrm{~mm})$ e coluna CN-10 (300 mm x $5 \mu \mathrm{m}$ x $4 \mathrm{~mm}$ ) foi utilizado na separação e identificação de cumarina e bergapteno.

Para a análise quantitativa e qualitativa do limoneno, acetato de linalila e linalol utilizou-se o cromatógrafo de fase gasosa HP 5890 II equipado com detector de ionização de chama e sistema de injeção split-splitless em coluna capilar de sílica fundida (fase estacionária Metil silicone, equivalente a SE-30 (HP-1 25m x 0,20mm x $0,33 \mu \mathrm{m})$.

\section{4 - Análise cromatográfica}

Para a análise da fração oxigenada e do limoneno foi utilizada a cromatografia de fase gasosa, sendo o hidro- gênio empregado como gás carreador a um fluxo de 0,97mL. min ${ }^{-1}$, e sistema de injeção tipo "split" na proporção de 284:1. A temperatura inicial da coluna foi de $75^{\circ} \mathrm{C} / 5$ minutos, aumentando até $150^{\circ} \mathrm{C}$ a uma razão de $3,0^{\circ} \mathrm{C} / \mathrm{min}$. e permanecendo assim durante $5 \mathrm{minu}-$ tos. As temperaturas do injetor e detector foram $250^{\circ} \mathrm{C} \mathrm{e}$ $300^{\circ} \mathrm{C}$, respectivamente. Curvas de calibração com padrão interno (tetradecano) foram utilizadas na quantificação dos oxigenados, conforme descrito por COELHO [4].

$\mathrm{Na}$ separação e quantificação do bergapteno, utilizou-se a cromatografia liquida monitorada a $315 \mathrm{~nm}$ e fase móvel constituida de hexano - isopropanol (94:6 v/ v) com fluxo de $0,8 \mathrm{mLmin}^{-1}$ de acordo com método descrito por FISHER e TRAMA [7].

\section{5 - Processo de extração}

Aproximadamente $20 \mu \mathrm{L}$ do óleo essencial de bergamota foram adsorvidos em 100mg de sílica gel $70-$ 300 mesh e acondicionados em envelopes de papel-filtro de tamanho apropriado e colocados no interior da célula extratora. Para a otimização do processo variaram-se os seguintes parâmetros: temperatura de extração, fluxo de $\mathrm{CO}_{2}$, densidade do $\mathrm{CO}_{2}$, tempo de extração e temperatura do coletor. Após cada extração, o coletor a $40^{\circ} \mathrm{C}$ foi lavado com hexano na pré-extração para remoção de substâncias interferentes e etanol na extração da fração oxigenada $(1,5 \mathrm{~mL})$.

\section{3 - RESULTADOS E DISCUSSÕES}

Pelas análises cromatográficas do limoneno, linalol, acetato de linalila, tetradecano, bergapteno e cumarina, determinaram-se os seguintes tempos de retenção: 7,2 ; $10 ; 16 ; 22,2 ; 14,4$ e 21,5min, respectivamente, e as correspondentes curvas de calibração (coeficiente de correlação) foram: $\mathrm{Y}=0,7563 \mathrm{x}+0,0069(\mathrm{r}=0,9967), \mathrm{Y}=$ $0,51 \mathrm{x}+0,0118(\mathrm{r}=0,9969), \mathrm{Y}=0,55 \mathrm{x}+0,019(\mathrm{r}=0,9972)$ e $Y=66,203 x+0,0466(r=0,9962)$. O teor desses componentes no óleo de bergamota bruto foi calculado a partir das curvas de calibração e apresentou os seguintes valores (mg/g amostra): limoneno $(267,33)$, linalol $(113,13)$, acetato de linalila $(372,18)$ e bergapteno $(1,14)$. As condições testadas na otimização dos parâmetros foram: densidades de 0,20; 0,25 e 0,35g. $\mathrm{mL}^{-1}$; temperaturas de extração 40, 50, 60 e $70^{\circ} \mathrm{C}$ para a remoção do limoneno; densidades: 0,5; 0,6; 0,7 e 0,85g. $\mathrm{mL}^{-1}$ a 40, 50 e $60^{\circ} \mathrm{C}$, para extração da fração oxigenada.

\section{1 - Efeito da temperatura}

Não foi utilizada temperatura acima $70^{\circ} \mathrm{C}$ em virtude da degradação dos constituintes do óleo [17]. Com base nos resultados, pode-se dizer que tanto o aumento da temperatura como o da densidade acarretaram maior remoção do limoneno, (Figura 2), significando maior poder de solvatação, pelo aumento da pressão de vapor ocasionado pela elevação da temperatura. O maior índice de recuperação de limoneno (86\%) foi obtido na densidade $0,35 \mathrm{~g} \cdot \mathrm{mL}^{-1}$ (120bar) e a temperatura de $70^{\circ} \mathrm{C}$, mas, nestas condições, houve também maior remoção da fra- 
ção oxigenada (39,07\% de linalol e 50,86\% de acetato de linalila). Isto significa que, apesar de ter conseguido grande capacidade de extração, o fracionamento entre os componentes de interesse no óleo foi mínimo, possivelmente pela formação de uma mistura homogênea entre terpenos, compostos oxigenados e gás carbono supercrítico. Assim, a melhor condição para remover o limoneno com menor retirada de linalol e acetato de linalila foi quando se usou a densidade $0,25 \mathrm{~g} \cdot \mathrm{mL}^{-1}$ (77bar) e temperatura de $40^{\circ} \mathrm{C}$.
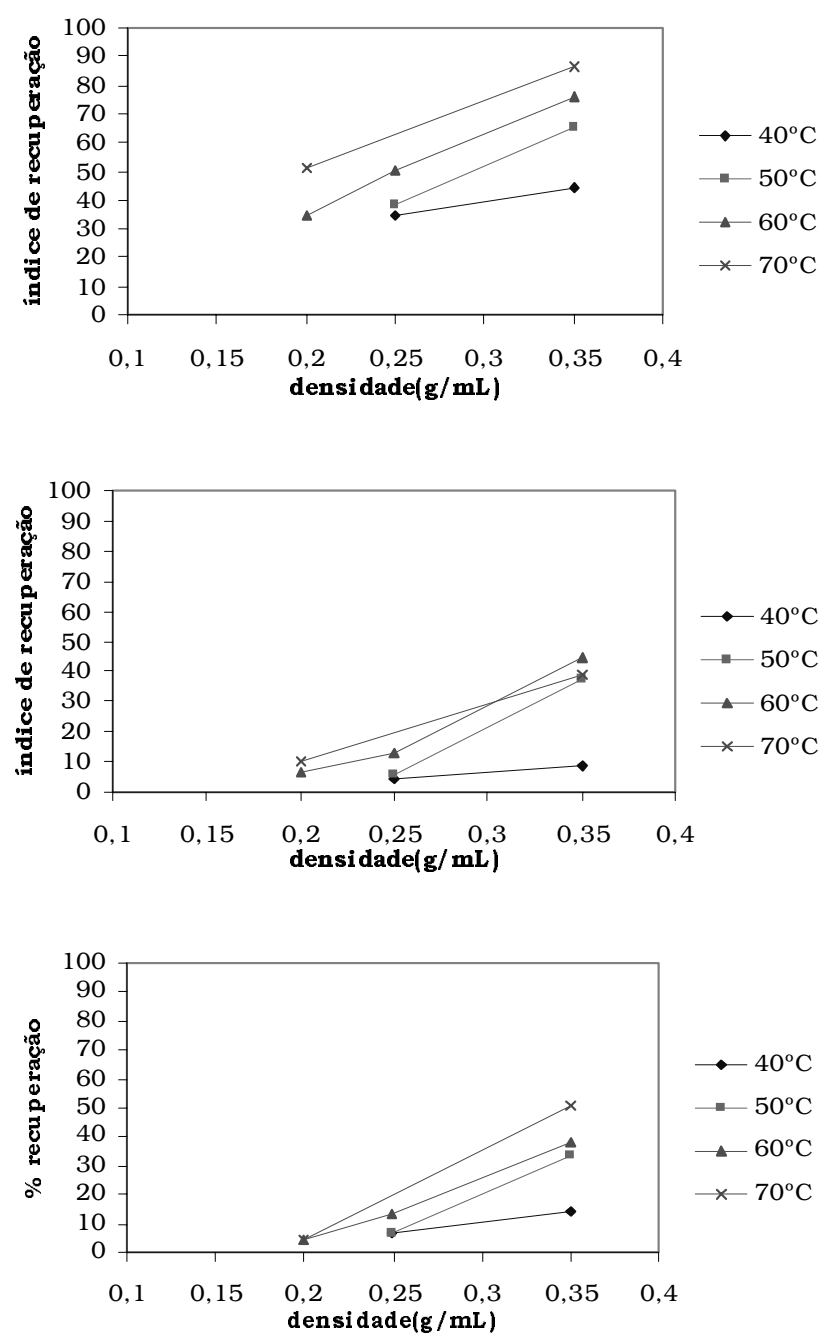

FIGURA 2. Índice de recuperação de limoneno (a), linalol (b) e acetato de linalila (c) nos extratos obtidos por $\mathrm{CO}_{2}$ supercrítico, em diferentes condições de temperatura e densidade.

\section{2 - Tempo de extração e fluxo}

As extrações foram conduzidas para otimizar o fluxo de $\mathrm{CO}_{2}$ e tempo de extração. As melhores condições de fluxo de $\mathrm{CO}_{2}$ e tempos de extração dinâmica foram $2 \mathrm{~mL} \cdot \mathrm{min}^{-1}$ e 15 minutos, respectivamente, sem a necessidade de extração estática, obtendo-se, assim, maior remoção do limoneno. Tempo de extração mais longo e fluxo maior nas condições estudadas, resultaram em perdas da fração oxigenada, além da ocorrência de dessorção de ambos os componentes, ocasionada pela saturação da sílica, os quais foram removidos juntamente com o $\mathrm{CO}_{2}$. Em razão da alta volatilidade dos componentes extraídos, a temperatura baixa do coletor é de fundamental importância, pois das três estudadas $(0,5$ e $10^{\circ} \mathrm{C}$ ) a que melhor proporcionou a recuperação do limoneno foi a de $10^{\circ} \mathrm{C}$.
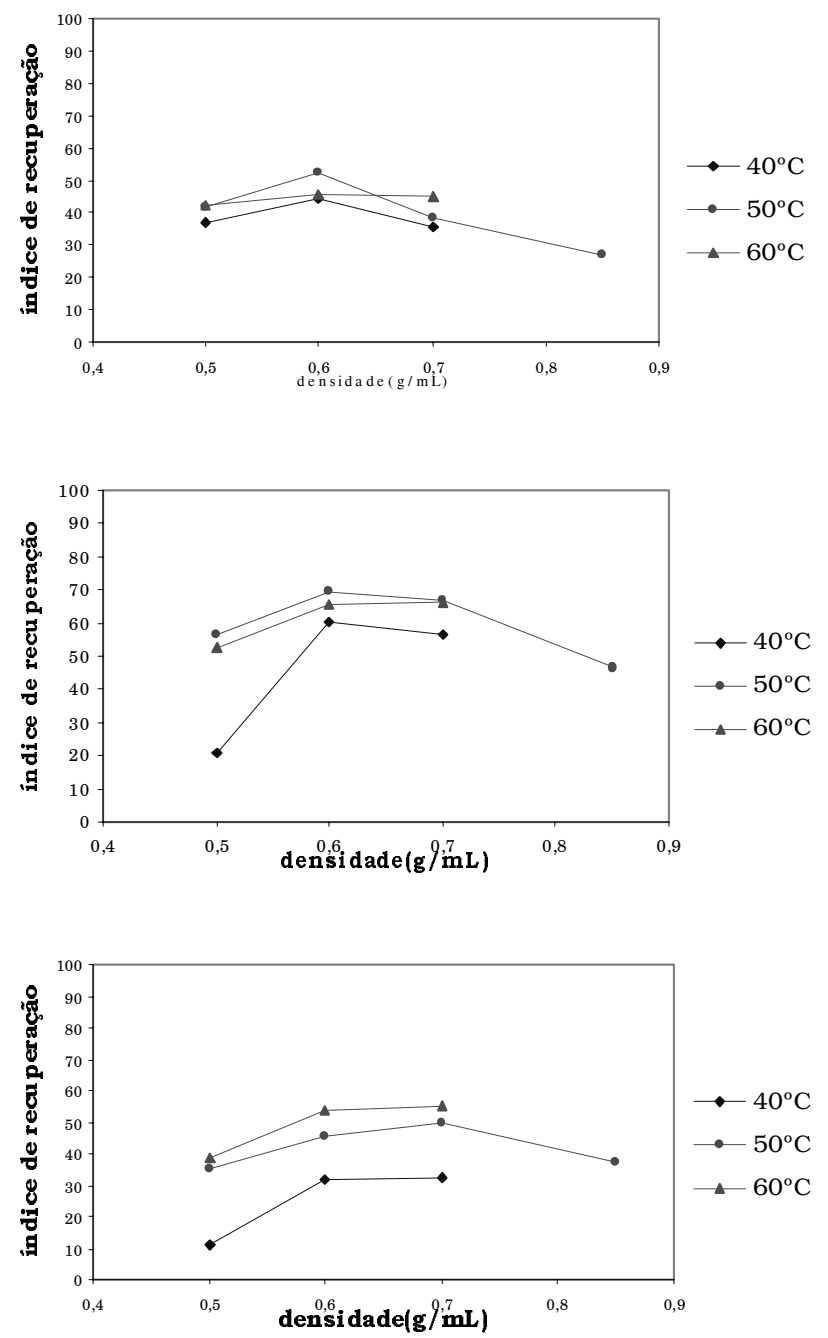

FIGURA 3. Índice de recuperação de limoneno(a), linalol(b) e acetato de linalila(c) nos extratos obtidos por extração supercrítica, em diferentes condições de temperatura e densidade.

Após a otimização das condições de pré-extração (deterpenação) do óleo essencial de bergamota, iniciouse a segunda etapa do experimento, com o objetivo de extrair a fração oxigenada, representada pelo linalol e acetato de linalila com quantidade mínima de limoneno e bergapteno. Observou-se que aumento da temperatura e da densidade proporcionou maior recuperação do linalol e acetato de linalila, e, para o limoneno, não se verificou aumento considerável na quantidade extraída (Figura 3). A silica-gel retém os oxigenados, permitindo 
que em baixa temperatura e pressão ocorra a extração do limoneno. Portanto, aumentando-se a temperatura e a pressão, foi possivel a eluição dos compostos oxigenados aderidos à sílica-gel.

A melhor condição para a extração da fração oxigenada, considerando menor quantidade de limoneno presente nesta fração, foi: $50^{\circ} \mathrm{C} / 0,70 \mathrm{~g} \cdot \mathrm{mL}^{-1}$ (151bar), fluxo de $\mathrm{CO}_{2}$ e tempo de extração dinâmica de $3 \mathrm{~mL} \cdot \mathrm{min}^{-1}$ e 15 minutos, respectivamente, não havendo a necessidade de tempo de extração estática. A melhor temperatura para o coletor foi de $10^{\circ} \mathrm{C}$, mantida em todas as etapas do fracionamento do óleo essencial de bergamota. Nessas condições obtiveram-se indices de recuperação de $49,88 \%$ para linalol e 66,90\% para acetato de linalila, além da presença de bergapteno em niveis-traço.

A presença de bergapteno em concentrações consideráveis foi observada somente nos extratos obtidos em temperaturas e densidades maiores. Pela maior afinidade desta substância com a silica-gel, a sua eluição só foi possivel em maiores temperaturas e densidades. A relação entre a concentração de compostos oxigenados (Co) e a concentração de limoneno $\left(C_{L}\right)$ na amostra inicial, foi de 1,81 e ao final do processo de extração a relação, $\mathrm{Co} / \mathrm{C}_{\mathrm{L}}$ foi de 3,0 evidenciando a concentração da fração oxigenada.

\section{4 - CONCLUSÕES}

Variando-se as condições de extração pôde-se remover quantidades substanciais de limoneno e, seqüencialmente, da fração oxigenada com teor reduzido de bergapteno. Verificou-se que, com o aumento da temperatura, diminuiu-se a eficiência do fracionamento, independentemente da pressão utilizada. A remoção mais eficiente de limoneno foi obtida a $40^{\circ} \mathrm{C} / 0,25 \mathrm{~g} \cdot \mathrm{mL}^{-1}$ (77bar) com fluxo de $2 \mathrm{~mL}$. $\mathrm{min}^{-1}$ e tempo dinâmico de $15 \mathrm{minu}-$ tos. Nestas condições, extraíram-se 55,65\% de limoneno contido no óleo de bergamota com perda de $8,36 \%$ de linalol e 3,59\% de acetato de linalila, não sendo evidenciada a presença de bergapteno. $\mathrm{Na}$ etapa de extração da fração oxigenada (linalol e acetato de linalila), observou-se que o efeito da temperatura foi maior que a pressão, proporcionado aumento do indice de recuperação. $\mathrm{Na}$ faixa de temperatura entre $50^{\circ} \mathrm{C}-60^{\circ} \mathrm{C}$, a variação na quantidade extraída foi muito pequena. Portanto, as melhores condições foram $50^{\circ} \mathrm{C} / 0,70 \mathrm{~g} \cdot \mathrm{mL}^{-1}$ (151bar) com fluxo de extração de $3 \mathrm{~mL} \cdot \mathrm{min}^{-1}$ e tempo dinâmico de 15 minutos. Nestas condições, extrairam-se 51,97\% de linalol e 69,38\% de acetato de linalila.

\section{5 - REFERÊNCIAS}

[1] BARTH, D., CHOUCHI, D., DELLA PORTA, G., REVERCHON, E. \& PERRUT, M. Desorption of lemon peel oil by supercritical carbon dioxide: deterpenation and psoralens elimination. The Journal of Supercritical Fluids, v.7, p. 177 - 183, 1994.

[2] BRADDOCK, R. J. By-products of Citrus fruit. Food Technology, v.49, n.9, p.74-77, 1985.

[3] CHOUCHI, D., BARTH, D., REVERCHON, E. \& DELLA PORTA, G. Supercritical $\mathrm{CO}_{2}$ desorption of bergamot peel oil. Ind. Eng. Chem. Res., v.34, n. 12, p.4508-4513, 1995.
[4] COÊLHO, S.R.M. Fracionamento do óleo essencial de limão adsorvido em sílica gel pelo dióxido de carbono supercrítico. Viçosa, 1998. 68p. Dissertação. Departamento de Tecnologia de Alimentos, Universidade Federal de Viçosa (UFV).

[5] DUGO, G. The composition of the volatile fraction of the italian citrus essential oils. Perfumer \& Flavorist, v. 19, n.11, p. $29-51,1994$.

[6] DUGO, P., MONDELO, L., BARTLE, K. D., CLIFFORD, A. A., BREEN, D. G. A. \& DUGO, G. Deterpenation of sweet orange and lemon essential oils with supercritical carbon dioxide using silica gel as adsorbent. Flavour and Fragrance Journal, v. 10, p.51 - 58, 1995.

[7] FISHER, J. F. \& TRAMA, L. A. High-performance liquid chromatography determination of some coumarins and psoralens found in citrus peel oils. Journal of Agriculture and Food Chemistry, v.27, n.6, p.1334 1337, 1979.

[8] GUENTHER, E. The Essential Oils. Vol.II. Robert E. Krieger Publishing Company, New York, 1975.

[9] GUENTHER, E. The Essential Oils. Vol.III. Robert E. Krieger Publishing Company, New York, 1974.

[10] KING, J. W. Extração utilizando fluido no estado supercrítico. Cosmetics \& Toiletries, v.4, p.34 - 38, 1992.

[11] LAWRENCE, B. M. Progress in essential oils: coumarins and psoralens in citrus oils. Perfumer \& Flavorist, v.7, n.6, p.57-65, 1982.

[12] MAZZA, G. Ètude sur la composition aromatique de l'huile essentielle de bergamote (Citrus Aurantium subsp. Bergamia Risso et Poiteau Engler) par chromatographie gazeuse et spectrométrie de masse. Journal of Chromatography, v.362, p.87-99, 1986.

[13] PANGBORN, R. M. \& RUSSEL, G. F. Essential oils and oleoresins. In: Principles of Food Science: Flavors, Part I: Food Chemistry, Marcel Dekker, New York and Basil, 1976.

[14] POIANA, M., REVERCHON, E., SICARI, V. MINCIONE, B. \& CRISPO, F. Supercritical carbon dioxide extraction of bergamot oil: bergapten content in the extracts. Italian Journal of Food Science, v.6, n.4, p.459-466, 1994.

[15] SMith, M. J. A., POUlTon, G. A., BARKER, M. \& MILDENBERGER, M. 5- Methoxypsoralen as ingredient in several suntan preparations, has lethal, mutagenic and clastogenic properties. Nature, v.285, p.407 - 409, 1980.

[16] TEMELl, F., BRADDOCK, R. J., CHEN, C.S. \& NAGY, S. Supercritical carbon dioxide extraction of terpenes from orange essential oil. In: Supercritical carbon dioxide extraction and chromatography. American Chemical Society, 1988. p. 109 - 124. (ACS Symposium Series, 366).

[17] TEMELLI, F., O'CONNELL, J. P., CHEN, C. S. \& BRADDOCK, R.J. Termodynamic analysis of supercritical carbon dioxide extraction of terpenes from cold-pressed orange oil. Industrial Engineering and Chemical Research, v.29, n. 4, p.618 - 624, 1990.

[18] YOUNG, A. R., WALKER, S. L., KINLEY, J. S., PLASTOW, S. R., AVERBECK, D., MORLIËE, P. \& DUDERTRET, L. Phototumorigenesis studies of 5-methoxypsoralen in bergamot oil: evaluation and modification of risk of human use in an albino mouse skin model. Journal of Photochemistry and Photobiology, v.7, p.231-250, 1990.

[19] YURKOW, E. J. \& LASKIN, J.D. Characterization of a photoalkylated psoralen receptor in HeLa cells. Journal of Biological Chemistry, v.262, n. 18, p.8439-8442, 1987.

\section{6 - AGRADECIMENTOS}

Ao CNPq pela bolsa de pesquisa concedida. 